\title{
Experimental Study on Bond-Slip Behavior between H-Shaped Steel and Gypsum Cover in SGFCG
}

\author{
Tao Sun $\mathbb{D D}^{1}{ }^{1}$ Kejian Ma, ${ }^{2}$ Zhihua Chen, ${ }^{3}$ Jin Chen $\mathbb{D D}^{1},{ }^{1}$ and Yuhao Zhu ${ }^{1}$ \\ ${ }^{1}$ Military Installation Department, Army Logistic University of PLA, Chongqing 401331, China \\ ${ }^{2}$ The Spatial Research Center of Guizhou University, Guiyang 550003, China \\ ${ }^{3}$ Civil Engineering School of Tianjin University, Tianjin 300072, China \\ Correspondence should be addressed to Jin Chen; lcx2002216@163.com
}

Received 24 October 2019; Revised 5 February 2020; Accepted 21 February 2020; Published 25 June 2020

Academic Editor: İlker Bekir Topçu

Copyright (C) 2020 Tao Sun et al. This is an open access article distributed under the Creative Commons Attribution License, which permits unrestricted use, distribution, and reproduction in any medium, provided the original work is properly cited.

\begin{abstract}
Nine push-out specimens of H-shaped steel with gypsum cover (HSG) are designed to study the bond-slip behavior between steel and gypsum in steel grid frame filling with cast-in-situ gypsum (SGFCG). Three main factors including gypsum compression strength $\left(f_{\text {cu }}\right)$, gypsum cover thickness $\left(C_{s}\right)$, and steel-gypsum connected length $\left(l_{a}\right)$ are considered. It is shown by the test results that the ultimate average bond strength is within [0.333-0.456] $\mathrm{MPa}$, and the residual strength is about $90-98 \%$ of the ultimate strength. Both gypsum cover thickness and steel-gypsum connected length have evident influence on the bond strength, while the effect of gypsum compression strength is not obvious. Based on the test data, the formulas of average bond strength characteristics $\left(\overline{\tau_{s}}, \overline{\tau_{u}}\right.$, and $\left.\overline{\tau_{r}}\right)$ and slip characteristics $\left(S_{u}\right.$ and $\left.S_{r}\right)$ are established by statistical fitting. Furthermore, the bond-slip constitutive relationship $(\bar{\tau}-S)$ is recommended.
\end{abstract}

\section{Introduction}

As a new type of lateral resisting structure, steel grid frame filling with cast-in-situ gypsum (SGFCG) is widely applied in industrial and civil constructions. Figure 1 shows an engineering practice of a multistorey structure. As presented in Figure 2, SGFCG has two basic components: steel grid frame consisted of numerous of small members and enclosure wall cast by postpoured industrial gypsum. Since all the steel members are covered by the thick gypsum wall, SGFCG presents several advantages comparing to the pure steel structure, such as steel is well protected from fire and corrosive medium; also, good thermal isolation is another favorable feature of SGFCG. Furthermore, application of SGFCG brings considerable environmental benefits since the construction of the wall consumes a large amount of industrial gypsum waste (such as desulfurization gypsum and phosphogypsum).

Up to now, a large number of research studies had been carried out to investigate the ultimate capacity, structural analysis, and design method of SGFCG structures [1-5].
However, the effects of the gypsum wall were not considered. It still remains uncertain that whether the gypsum cover can work with the steel members inside together or not. If there is a great slip between them, the gypsum cover will crack and fall off. Then, the advantages mentioned above will vanish. Therefore, the bond-slip response between steel members and gypsum cover is significant to the basic understanding of the overall behavior of SGFCG, which is necessary to be carefully studied.

At present, there is no research on bond-slip behavior between steel and gypsum yet. However, for steel-reinforced concrete (SCR) structures, abundant of studies on bond-slip behavior between steel and normal concrete had been carried out. Bryson and Mathey [6], Hawkins [7], Roeder [8], Sun and Wang [9], and Hong and Jiang [10] concluded that there was a direct relationship between the bond strength and the concrete strength. Bryson and Mathey [6] specifically studied the influence of the steel surface treatment on the bond strength between shaped steel and concrete. The results showed that the bond strength was significantly improved after sandblasting the shaped steel surface. Sun 


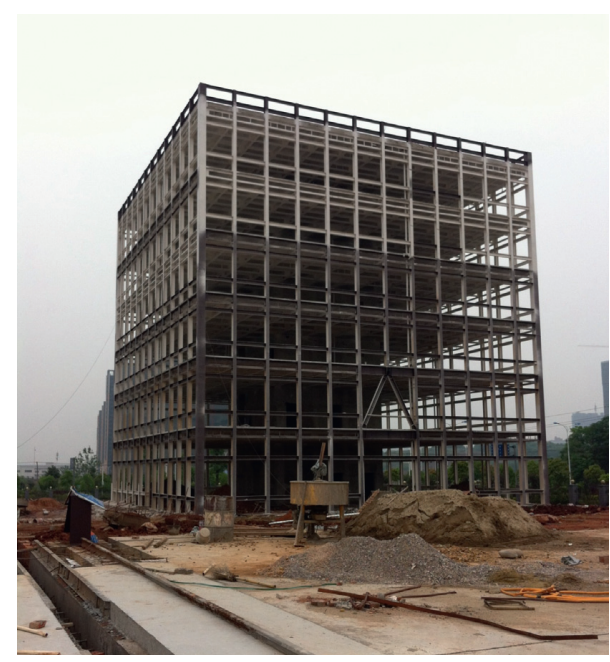

FIGURE 1: Engineering practice of SGFCG.

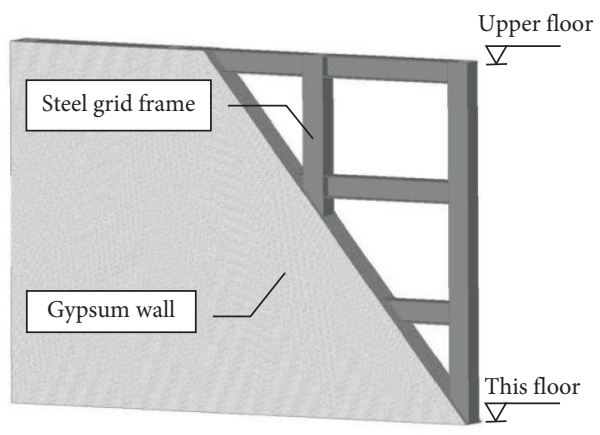

Figure 2: Two components of SGFCG.

and Wang. [9] and Hong and Jiang [10] found that the bond strength of the steel-reinforced concrete increased constantly as the concrete cover thickness increased. However, when the concrete cover thickness reached a certain value, the effect on the bond strength was not obvious. Yang et al. [11] studied the influence of four main factors including concrete strength, embedded length, lateral hoop ratio, and concrete cover thickness on the bond-slip performance of SRC and proposed a mathematical model of the constitutive relationship between average bond stress and load-end slip. Zheng et al. [12] studied the bond strength distribution along the connected length of SRC and proposed the calculation formula of bond strength and bond slip. Chen et al. [13] conducted nine push-out tests to study the bond-slip behavior between checkered steel and concrete in CFCST structures. The experimental results showed that the height of the checkered pattern had significant influence on ultimate average bond strength, and the results of the basic bond-slip constitutive model agreed well with the test results. Yang et al. [14] found that the concrete strength grade, the length of the embedded steel section, the lateral stirrup ratio, and the thickness of the concrete protective layer were the main factors affecting the bond-slip performance. The internal steel strains were exponentially and linearly distributed in the rising and the falling stage of the applied load, respectively. Zheng et al. [15] carried out outsourcing steel-reinforced concrete launch test. Experimental results have revealed that the concrete strength grade, contact surface state, and contact length were the important factors affecting the bond strength. Liu et al. [16] conducted twentyseven standard push-out tests of SRRC specimens. It was shown that the failure mechanism and the failure pattern of SRRC are similar to SRC, which are composed of the noslipping, slipping, destroying, decline, and residual stage. The average bond strength of SRRC was influenced by RCA, RAC strength, and embedment length, as well as the thickness of concrete cover of SRC by some degree. Bai et al. [17] had investigated the bond behavior of $\mathrm{H}$-shaped steel embedded in engineered cementitious composites (ECCs). The results showed that the critical bond stress increased with the volume fraction of the PVA fiber and increasing the ECC cover thickness can significantly enhance the ultimate bond stress and residual bond stress. However, the ultimate bond stress declined slightly when the embedded length was increased. The stirrup reinforced ratio had little influence on the critical bond stress.

The aforementioned research studies have shown that the major factors affecting the bond performance of SRC are concrete strength, concrete cover thickness, profile surface condition, lateral hoop ratio, connected length, and sectionheight ratio. Based on the above experimental studies of SRC, nine push-out specimens of HSG (H-shaped steel with gypsum cover) have been designed to investigate the bondslip behavior between steel and gypsum in SGFCG. The loadslip curves, average bond strength, and slip failure modes were obtained. According to regression of the test results, calculation formulas of average bond strength characteristics $\left(\overline{\tau_{s}}, \overline{\tau_{u}}\right.$, and $\left.\overline{\tau_{r}}\right)$, slip characteristics $\left(S_{u}\right.$ and $\left.S_{r}\right)$, and bond-slip constitutive relationship were derived, which lay a foundation for the subsequent finite element studies.

\section{Test Scheme}

The tests were carried out on the 12 ton pressure testing machine in the structure laboratory of Tianjin University. The loading device is shown in Figure 3. The specimen had squared cross section, with side length $d$ as $100 \mathrm{~mm}$. In the loading system, the top side of the $\mathrm{H}$-shaped steel was fixed on the roof of the axial testing machine by a special fixture. The bottom side of the $\mathrm{H}$-shaped steel was free, and there was a gap of $50 \mathrm{~mm}$ to the loading plate of the testing machine. The top side of the gypsum cover was free, and the bottom side was subject to pressure upward transferred from the loading plate. During the installation of test specimens, the geometric alignment of specimens should be confirmed, and the loading surface should be kept in level, which ensured the specimens to bear axial pressure in the whole loading process. Dial gauges were installed at the load end and the free end of the gypsum cover to measure the relative slip between steel and gypsum, as illustrated in Figure 4.

Nine push-out specimens were designed by the orthogonal method. The effects of three parameters on the bond-slip performance, namely, gypsum compressive strength $\left(f_{\text {cu }}\right)$, gypsum cover thickness $\left(C_{s}\right)$, and steel-gypsum connected length $\left(l_{a}\right)$, were studied. The characteristics 


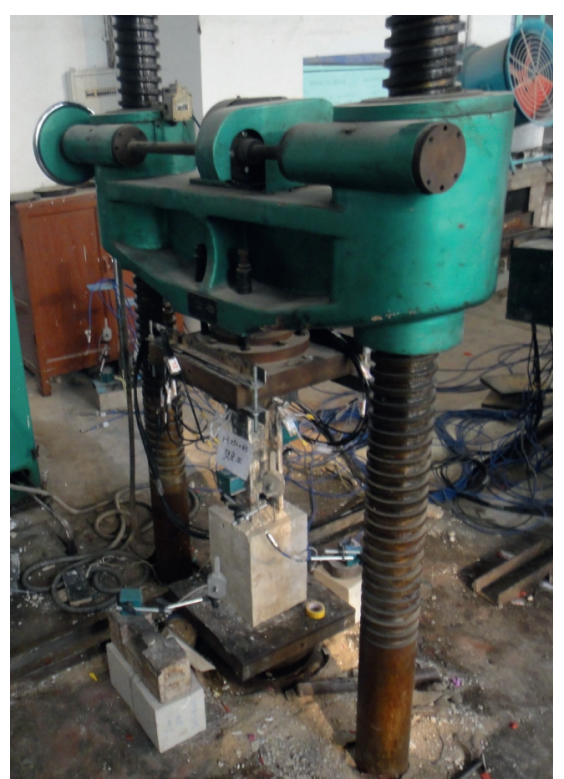

(a)

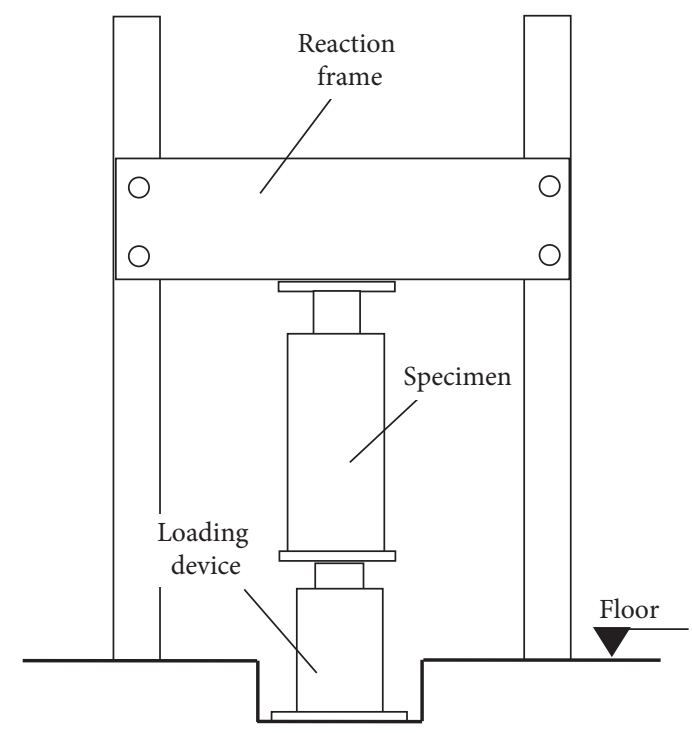

(b)

Figure 3: Experimental program: (a) testing machine; (b) testing system.

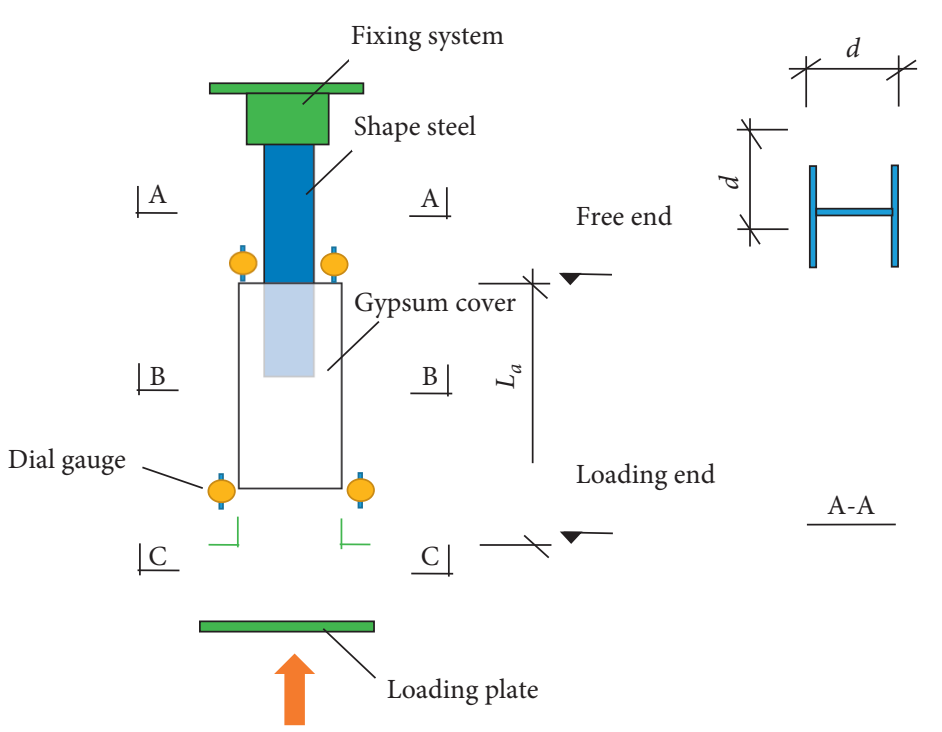

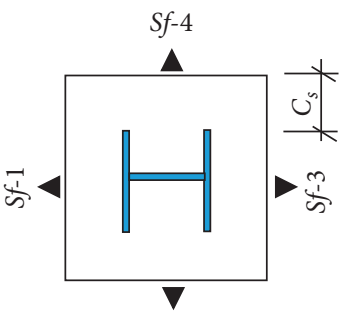
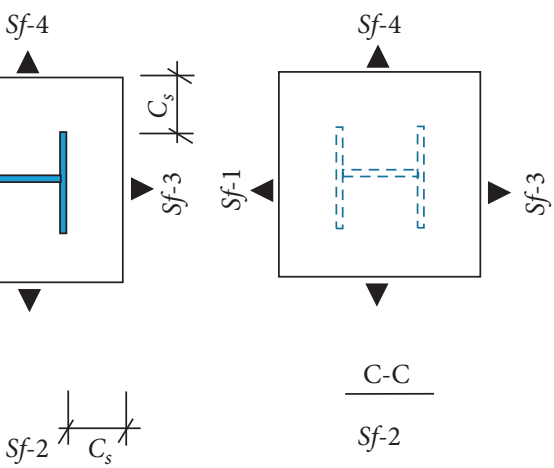

$\frac{\mathrm{C}-\mathrm{C}}{S f-2}$

Loading force

Figure 4: HSG push-out specimens and dial gauge distribution. $l_{a}$ is the steel-gypsum connected length, $C_{s}$ is the gypsum cover thickness, and $d$ is the $\mathrm{H}$-shaped steel section height. Sf-1, Sf-2, Sf-3, Sf- 4 are, respectively, the four vertical surfaces of the gypsum cover.

of HSG specimens of the push-out test are presented in Table 1, where $d$ is the H-shaped steel section height.

\section{Experimental Phenomena}

3.1. Failure Patterns. Throughout the loading process, for specimens C-1 and C-4, the relative slip at the free end or the load end was not observed even when the bottom side of gypsum finally crashed. The possible reason might be that the connected length of these two specimens was long enough so that the interfacial friction force was able to resist
TABLE 1: Characteristics of HSG specimens.

\begin{tabular}{lcccc}
\hline Specimen no. & $f_{\text {cu }}(\mathrm{MPa})$ & $C_{s}(\mathrm{~mm})$ & $l_{a}(\mathrm{~mm})$ & $d(\mathrm{~mm})$ \\
\hline C-1 & 8.41 & 35 & 750 & 100 \\
C-2 & 8.41 & 45 & 300 & 100 \\
C-3 & 8.41 & 55 & 250 & 100 \\
C-4 & 13.43 & 35 & 450 & 100 \\
C-5 & 13.43 & 45 & 350 & 100 \\
C-6 & 13.43 & 55 & 300 & 100 \\
C-7 & 13.22 & 35 & 300 & 100 \\
C-8 & 13.22 & 45 & 250 & 100 \\
C-9 & 13.22 & 55 & 350 & 100 \\
\hline
\end{tabular}


the compressive load of the gypsum. Hence, even the bottom gypsum of the specimens crushed, and there was no recognizable slippage between steel and gypsum. Apart from C1 and C4, noticeable slippage had been clearly observed for the other seven specimens, and the failure patterns can be concluded as the following two types.

Type 1: both ends began to slip at the same time (specimens C-2, C-6, C-7, and C-9).

There was no slip until the load reached $60-70 \%$ of the ultimate load. Both ends (load and free) of the specimen slipped with slight sound. Meanwhile, cracks were observed at the free end and developed towards the load end. Some cracks also appeared on the vertical surfaces of the gypsum cover. As reaching the ultimate load, the slippage increased faster than before, and the load began to decrease. Then, the main cracks became fulllength whose width increased gradually, but the number of cracks remained unchanged. Finally, the load of the test machine suddenly fell to $90-98 \%$ of the ultimate, and the specimens failed. At this time, the slippage increased much more rapidly, and the width of the main cracks increased to the maximum values.

Type 2: load end slipped first and the free end slipped afterwards (specimens C-3, C-5, and C-8).

At the beginning, there was no slip at both ends (load and free). As the load reached to $55-75 \%$ of the ultimate load, the load end first slipped with friction sounds, but no cracks appeared. When the load increased to $85-95 \%$ of the ultimate value, the free end also slipped. Meanwhile, the main cracks appeared at the tip of the flange and slowly developed from the free end to the load end with several branch cracks appearing. When the ultimate load was reached, the slip value increased rapidly without load growth, and the width of cracks kept increasing with no emerging of new cracks. Finally, the load suddenly fell to about $95 \%$ of the ultimate, and the specimens failed. At the same time, the slippage increased much more rapidly, and the width of the main cracks increased to the maximum values.

3.2. Cracking Patterns. Figures 5 and 6, respectively, show the cracks on vertical surfaces and free ends of the gypsum cover. Three types of cracking patterns can be concluded, as presented in Figure 7. It was found that the crack firstly appeared near the limb tips of flanges and gradually developed along diagonal lines to the outer surfaces of the gypsum cover. Then, the cracks gradually developed from the free end to the load end. For some test specimens, the gypsum connected to the flange outside peeled off (e.g., C-2, $\mathrm{C}-7$, and C-8), but the gypsum connected to the web and flange inside did not peel off. The main reason is that the gypsum is an expansion material. Hence, the gypsum connected to the web and flange inside is restrained in three directions, which provides much greater antislip force on the interface than the case that gypsum connected to the flange outside. Finally, the residual load maintains up to $90 \%$ of the ultimate strength.

\section{Experimental Results and Discussion}

4.1. Load-Slip Curve and Average Bond Strength Characteristics. The average bond strength of the interface between the steel and the gypsum cover from experimental results is defined by the following equation:

$$
\bar{\tau}=\frac{P}{C_{0} l_{a}},
$$

where $P$ is the applied load, $C_{0}$ is the steel section perimeter, and $l_{a}$ is the steel-gypsum connected length.

Figure 8, respectively, presents the $P$-S curves at the load end and the free end of specimens, from which we can find that the $P$ - $S$ curves are very similar to each other. The overall load-slip curves at the load end present the ascending stage and descending stage. According to equation (1), the average bond strength $(\bar{\tau})$ versus load-end slip $(S)$ curves is obtained. Based on this, we propose a typical $\bar{\tau}-S$ constitutive relationship model, as shown in Figure 9. There are two parts in the recommended model, namely, the ascending stage and descending stage. The ascending stage consists of non-slip stage (OA section) and varying slip stage ( $\mathrm{AB}$ section), and the descending stage is the $\mathrm{BCD}$ section. In section $\mathrm{OA}$, there is no slip. When the average bond stress reaches $\overline{\tau_{s}}$, the load end begins to slip, and the corresponding applied load is $P_{s}$. In section $\mathrm{AB}$, a linear relationship between average bond stress and load-end slip is defined. In this stage, the average bond strength increases significantly with the increase of slip until reaching the ultimate average bond strength $\left(\overline{\tau_{u}}\right)$. The corresponding ultimate applied load is $P_{u}$. According to the curve fitting for section $\mathrm{BCD}$, it shows the bilinear characteristics. Further analysis of the bilinear reveals that the average bond strength experiences the biggest drop at knee point $\mathrm{C}$ (defined as the damage point). $\overline{\tau_{r}}$ is the corresponding average bond strength, and the applied load is $P_{r}$. For brevity, we, respectively, fit the curves in front of point $C$ (section $\mathrm{BC}$ ) with the negative slope line and the curves behind point $\mathrm{C}$ (section $\mathrm{CD}$ ) with a horizontal line. To model the above curve characteristics, two characteristic slip values are defined: ultimate slip value $\left(S_{u}\right)$ and knee-point slip value $\left(S_{r}\right)$.

4.2. Influence of Different Factors on Average Bond Strength Characteristics $\left(\overline{\tau_{s}}, \overline{\tau_{u}}\right.$, and $\left.\overline{\tau_{r}}\right)$. The effects of three main parameters $\left(f_{\mathrm{cu}}, C_{s}\right.$, and $\left.l_{a}\right)$ on the average bond strength characteristics $\left(\overline{\tau_{s}}, \overline{\tau_{u}}\right.$, and $\left.\overline{\tau_{r}}\right)$ are discussed in this section. The average bond strength characteristics are shown in Table 2.

4.2.1. Effect of the Gypsum Cover Thickness. The effect of the gypsum cover thickness on $\overline{\tau_{s}}, \overline{\tau_{u}}$, and $\overline{\tau_{r}}$ is depicted in Figure 10 . The abscissa displays the relative-thickness value $\left(C_{s} / d\right)$, and the ordinate displays the average bond strength $(\bar{\tau})$. The gypsum cover thickness has an evident influence on characteristic average bond strengths. With the increasing of $C_{s} / d$, the average bond strength characteristics increase, which can be fitted as shown in the following equation: 

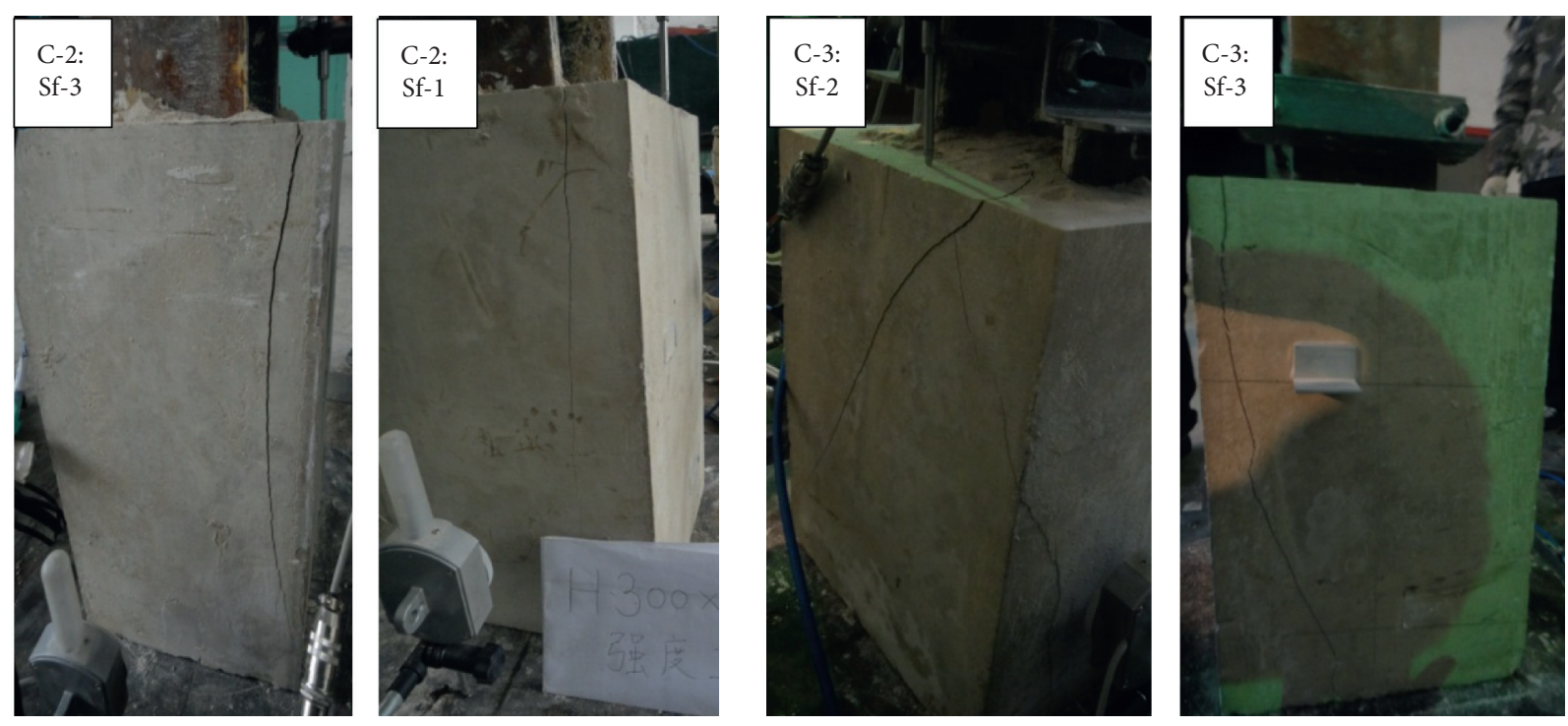

(a)
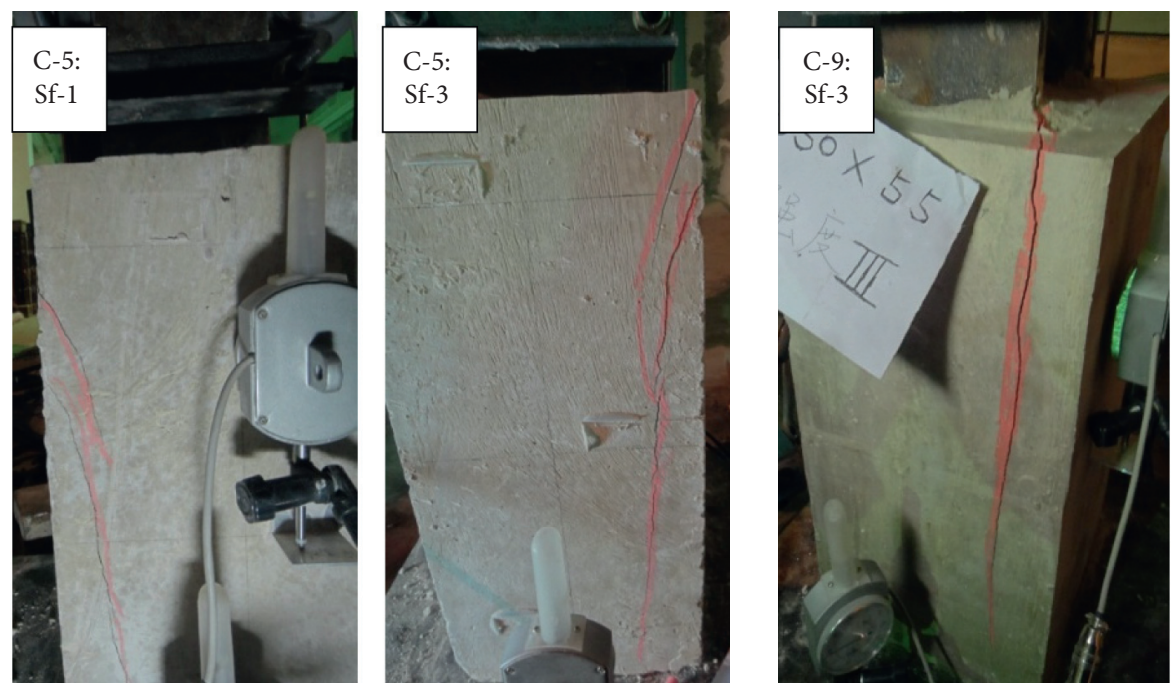

(b)

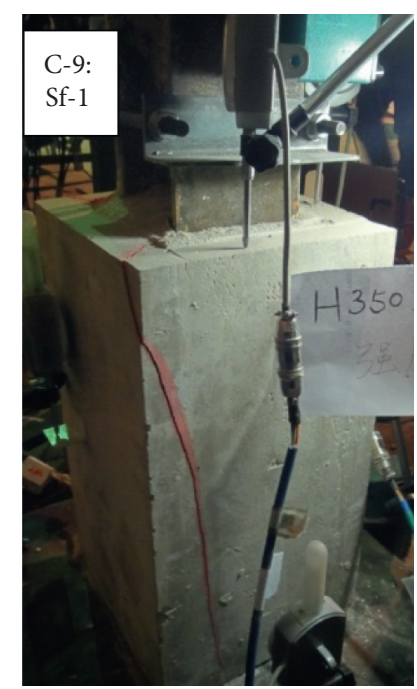

(c)

(d)

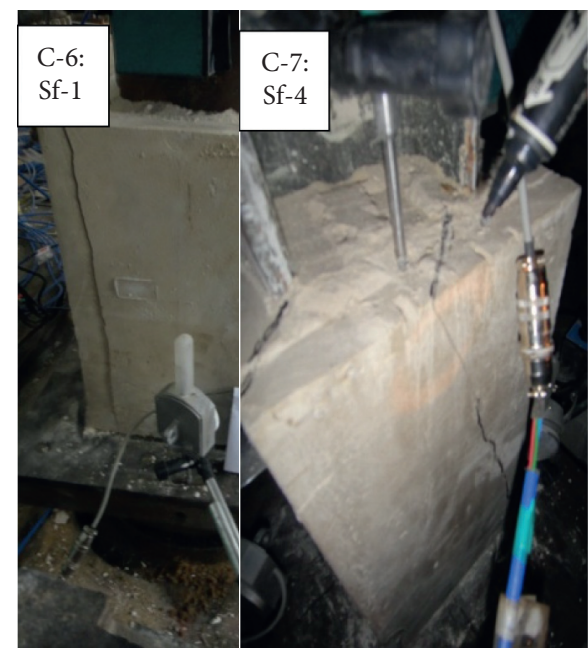

(e)
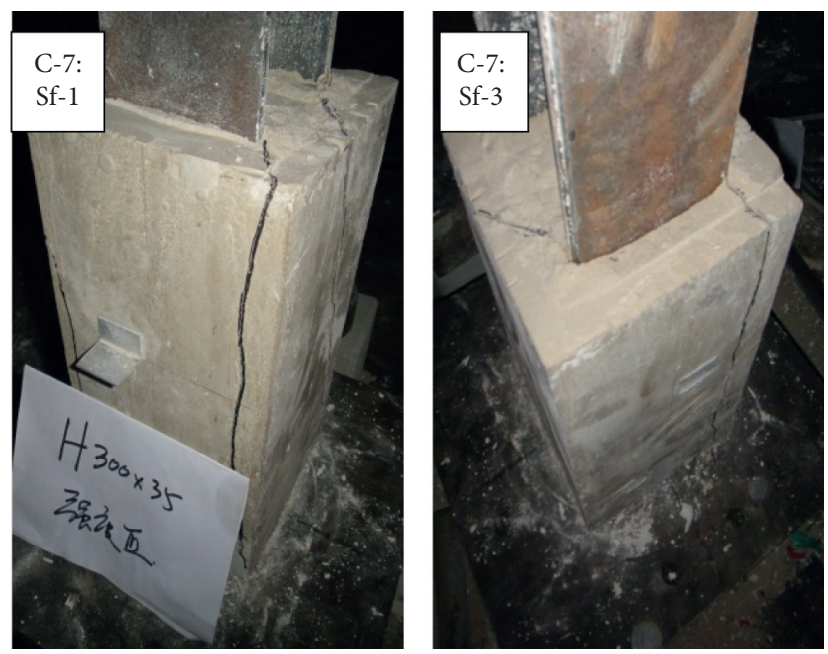

(f)

Figure 5: Continued. 

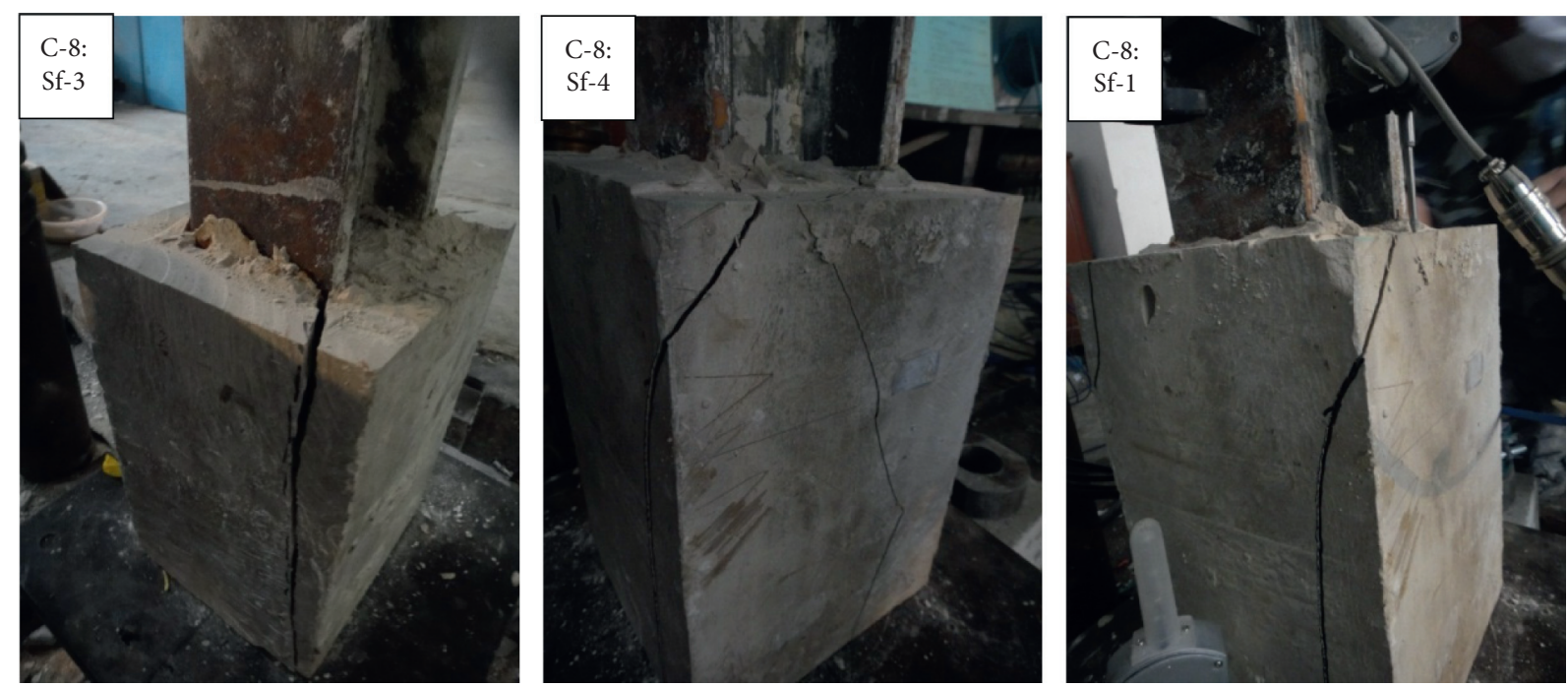

(g)

Figure 5: Crack development on vertical surfaces of the gypsum cover. (a) Specimen C-2. (b) Specimen C-3. (c) Specimen C-5. (d) Specimen C-9. (e) Specimen C-6. (f) Specimen C-7. (g) Specimen C-8.

$$
\left\{\begin{array}{l}
\overline{\tau_{s}}=\left(0.4444 \frac{C_{s}}{d}+0.0667\right) \cdot \mathrm{I} \\
\overline{\tau_{u}}=\left(0.6111 \frac{C_{s}}{d}+0.1213\right) \cdot \mathrm{I} \\
\overline{\tau_{r}}=\left(0.5000 \frac{C_{s}}{d}+0.1565\right) \cdot \mathrm{I}
\end{array}\right\},
$$

where $I$ is the unit strength value $(1 \mathrm{MPa})$.

4.2.2. Effect of the Steel-Gypsum Connected Length. The effect of the steel-gypsum connected length on $\overline{\tau_{s}}, \overline{\tau_{u}}$, and $\overline{\tau_{r}}$ is presented in Figure 11. The abscissa displays the relativeconnected length value $\left(l_{a} / d\right)$, and the ordinate displays the average bond strength $(\bar{\tau})$. It is clearly shown that there is a clear second-degree parabola relationship between the average bond strength characteristics and the relative-connected length. The average bond strength characteristics increase as the relative-connected length increases when the connected length is less than $300 \mathrm{~mm}$. When the length exceeds $300 \mathrm{~mm}$, the average bond strength characteristics decrease as the length increases.
The relationship between the average bond strength characteristics $(\bar{\tau})$ and the relative-connected length value $\left(l_{\mathrm{a}} / d\right)$ can be fitted as shown in the following equation:

$$
\left\{\begin{array}{l}
\overline{\tau_{s}}=\left[-0.1156\left(\frac{l_{a}}{d}\right)^{2}+0.7067 \frac{l_{a}}{d}-0.7911\right] \cdot I \\
\overline{\tau_{u}}=\left[-0.1416\left(\frac{l_{a}}{d}\right)^{2}+0.8743 \frac{l_{a}}{d}-0.9208\right] \cdot I \\
\overline{\tau_{r}}=\left[-0.1324\left(\frac{l_{a}}{d}\right)^{2}+0.8081 \frac{l_{a}}{d}-0.8245\right] \cdot I
\end{array}\right\} .
$$

4.3. Fitting of Average Bond Strength Characteristics. As shown in equation (4), the relationships between the gypsum cover thickness, the steel-gypsum connected length, and the average bond strength characteristics are considered comprehensively. Table 3 shows the fit results and test results of strength characteristics.

$$
\left\{\begin{array}{l}
\overline{\tau_{s}}=\left[-0.1431\left(\frac{l_{a}}{d}\right)^{2} \frac{C_{s}}{d}-0.0286\left(\frac{l_{a}}{d}\right)^{2}+0.8842 \frac{l_{a}}{d} \frac{C_{s}}{d}+0.1769 \frac{l_{a}}{d}-0.9604 \frac{C_{s}}{d}-0.1921\right] \cdot I \\
\overline{\tau_{u}}=\left[-0.0706\left(\frac{l_{a}}{d}\right)^{2} \frac{C_{s}}{d}-0.0406\left(\frac{l_{a}}{d}\right)^{2}+0.4406 \frac{l_{a}}{d} \frac{C_{s}}{d}+0.2533 \frac{l_{a}}{d}-0.2958 \frac{C_{s}}{d}-0.1701\right] \cdot I \\
\overline{\tau_{r}}=\left[-0.0084\left(\frac{l_{a}}{d}\right)^{2} \frac{C_{s}}{d}-0.0143\left(\frac{l_{a}}{d}\right)^{2}+0.0527 \frac{l_{a}}{d} \frac{C_{s}}{d}+0.0899 \frac{l_{a}}{d}-0.0877 \frac{C_{s}}{d}-0.1496\right] \cdot I
\end{array}\right\} .
$$




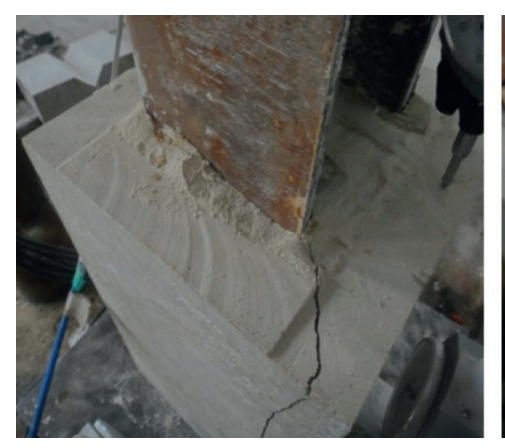

(a)
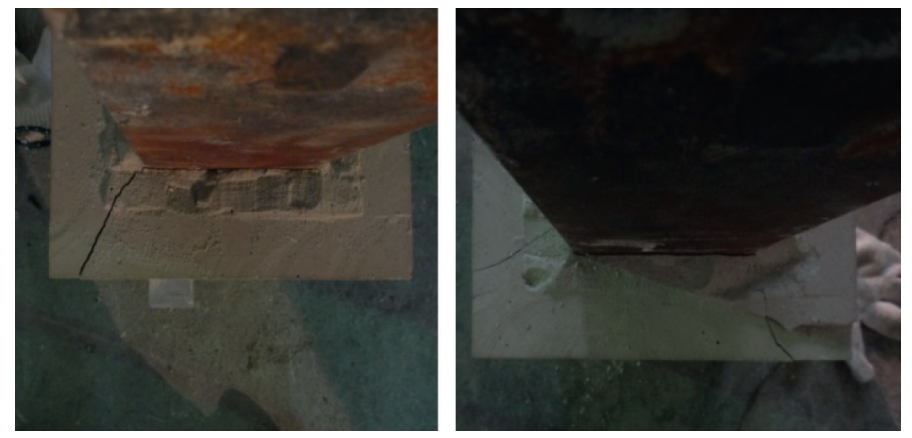

(c)

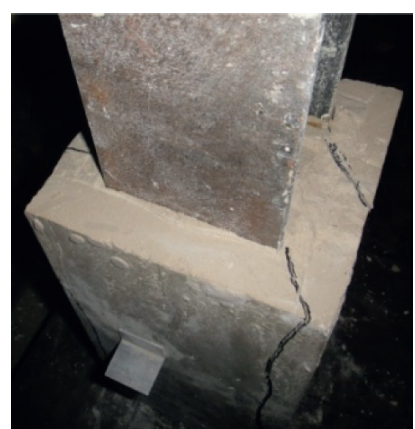

(e)
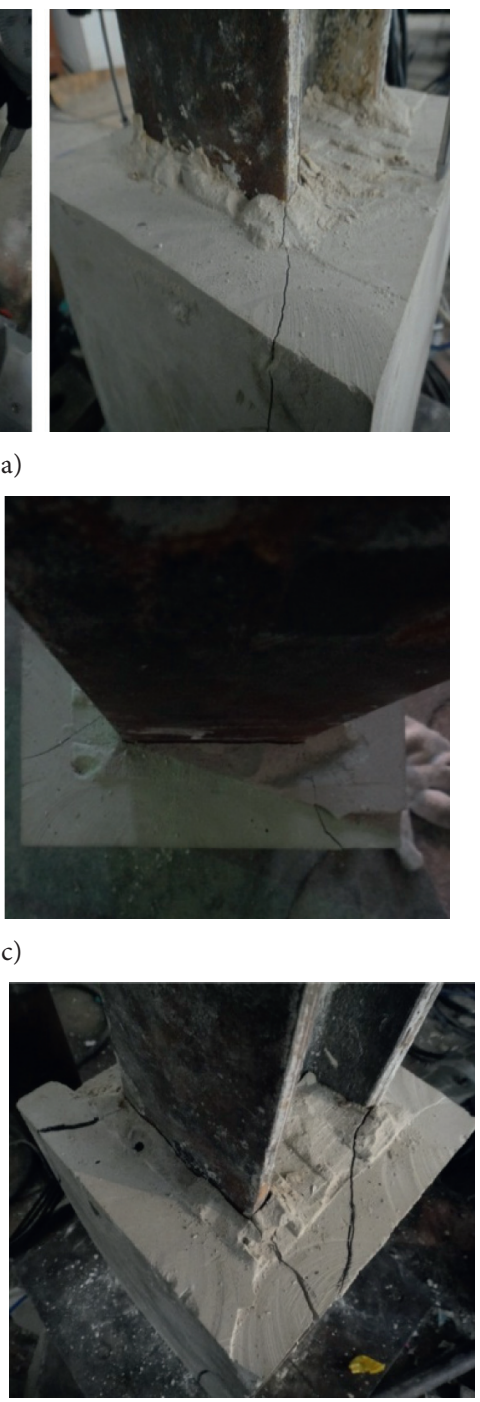

(f)

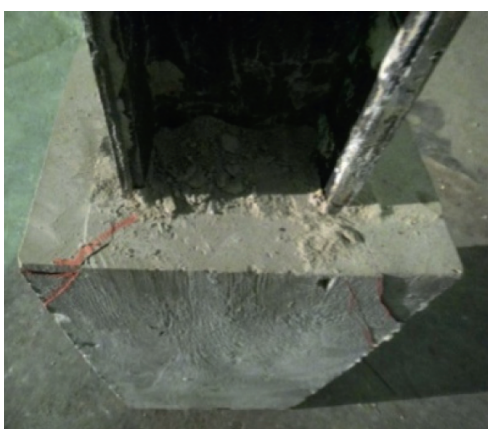

(b)

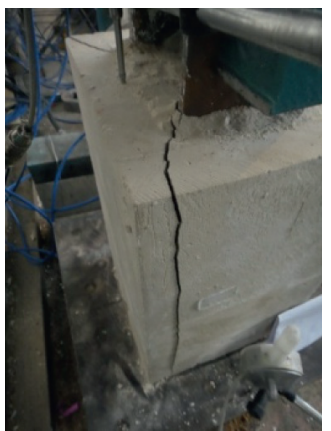

(d)

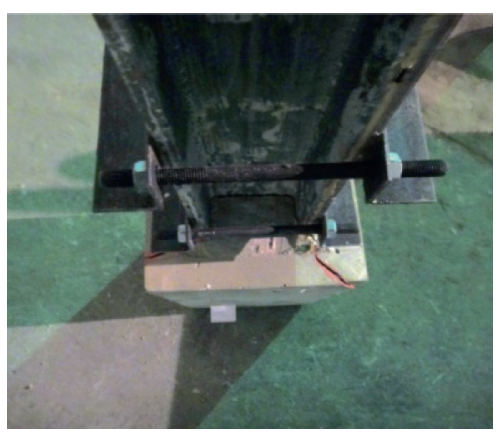

(g)

FIGURE 6: Crack development at the free end of the gypsum cover. (a) Specimen C-2. (b) Specimen C-5. (c) Specimen C-3. (d) Specimen C-6. (e) Specimen C-7. (f) Specimen C-8. (g) Specimen C-9.

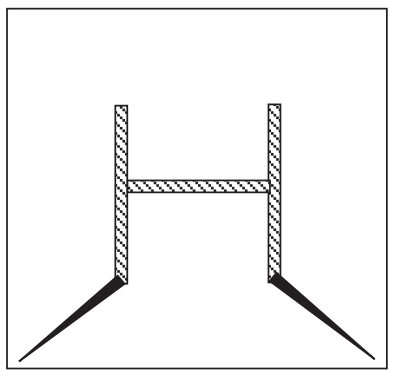

(a)

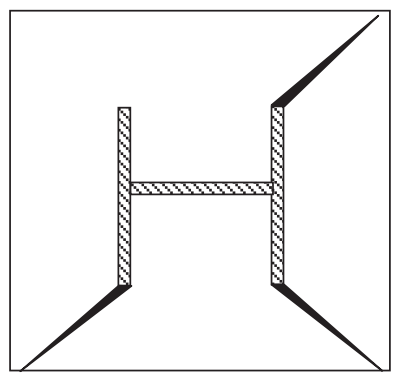

(b)

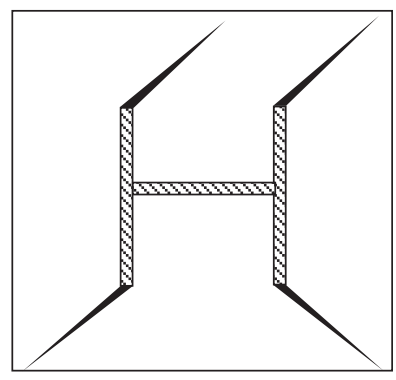

(c)

FIgURE 7: Three main crack distributions at the free end.

4.4. Fitting of Slip Characteristics. By analyzing the load-slip $(P-S)$ curves, the two slip characteristics $\left(S_{u}\right.$ and $\left.S_{r}\right)$ are defined in Figure 9. According to the above definition, the slip characteristics of push-out tests are summarized in Table 4.
By analyzing the data in Table 4, the fitting formulas of slip characteristics are obtained by considering the effect of the steel-gypsum connected length $\left(l_{a}\right)$ as the main parameter, as shown in the following equation: 


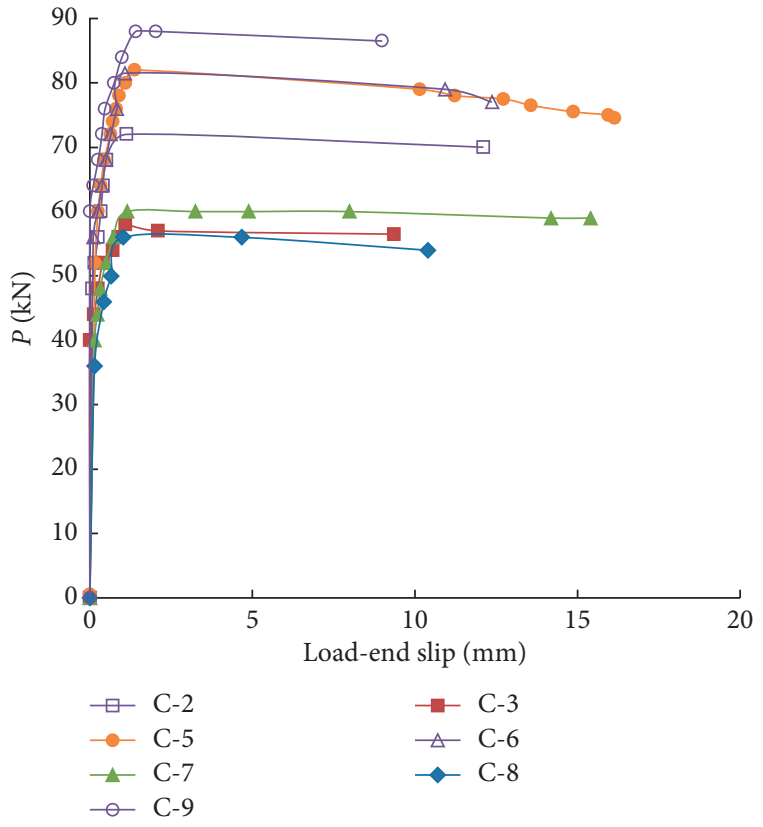

(a)

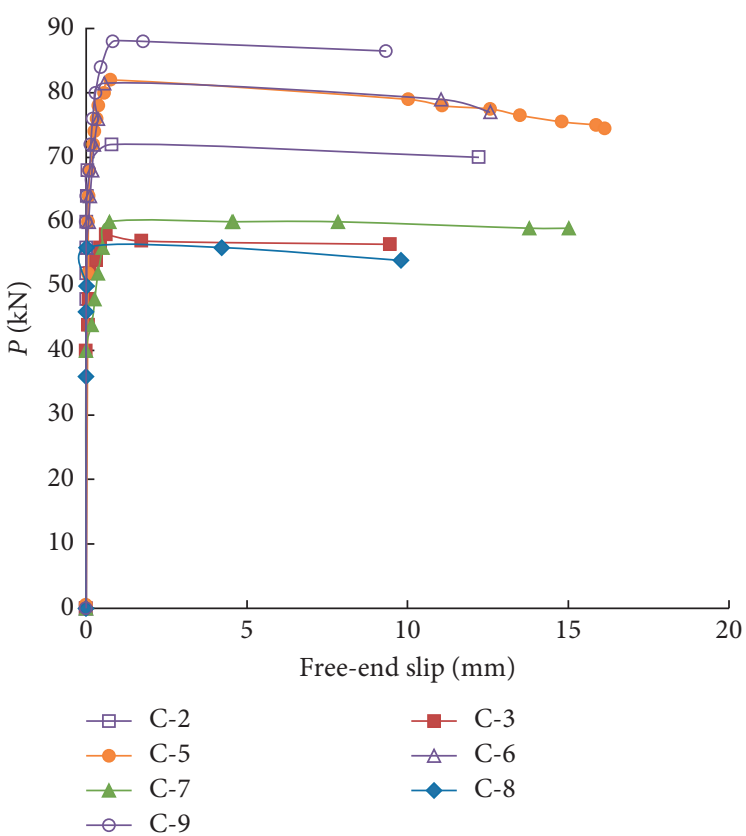

(b)

FIGURE 8: Load-slip curves.

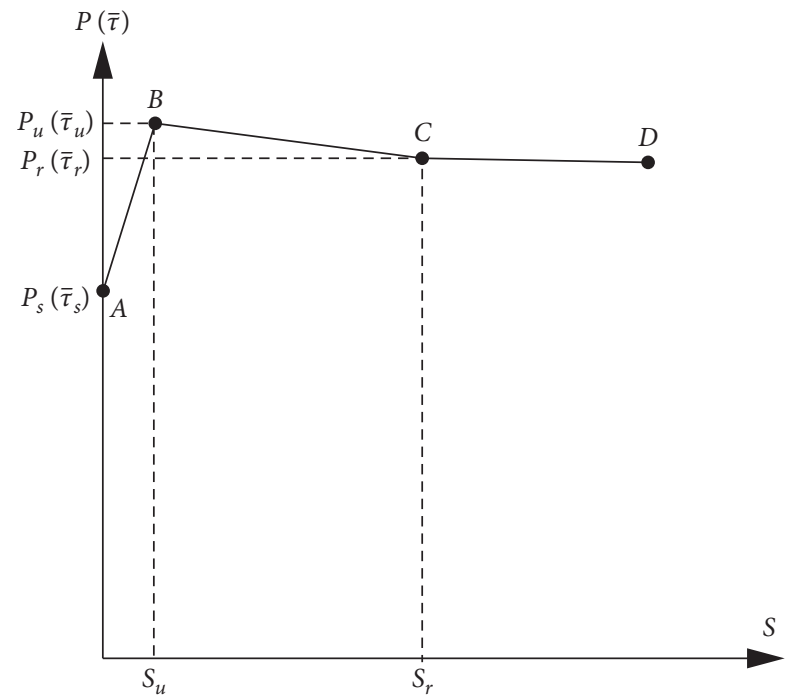

Figure 9: Typical constitutive relationship curve.

$$
\left\{\begin{array}{c}
S_{u}=3.961 \times 10^{-3} l_{a} \\
S_{r}=43.771 \times 10^{-3} l_{a}
\end{array}\right\} .
$$

\section{Bond-Slip Constitutive Relationship}

Based on equations (4) and (5), the relationship between average bond strength $(\bar{\tau})$ and slip $(S)$ in different stages is, respectively, given in equation (6). The OA segment is expressed in a vertical line where there is no slip, and the bond stress increases constantly. When $\bar{\tau}=\overline{\tau_{s}}$, the load end begins to slip. The $\mathrm{AB}$ segment is expressed as an oblique line
TABle 2: Load characteristics and average bond strength characteristics.

\begin{tabular}{lcccccc}
\hline $\begin{array}{l}\text { Specimen } \\
\text { no. }\end{array}$ & \multicolumn{2}{c}{ OA section } & \multicolumn{2}{c}{ AB section } & \multicolumn{2}{c}{ BCD section } \\
& $\begin{array}{c}P_{s} \\
(\mathrm{kN})\end{array}$ & $\begin{array}{c}\overline{\tau_{s}} \\
(\mathrm{MPa})\end{array}$ & $\begin{array}{c}P_{u} \\
(\mathrm{kN})\end{array}$ & $\begin{array}{c}\overline{\tau_{u}} \\
(\mathrm{MPa})\end{array}$ & $\begin{array}{c}P_{r} \\
(\mathrm{kN})\end{array}$ & $\begin{array}{c}\overline{\tau_{r}} \\
(\mathrm{MPa})\end{array}$ \\
\hline $\mathrm{C}-1$ & - & - & - & - & - & - \\
$\mathrm{C}-2$ & 48 & 0.2667 & 72 & 0.4000 & 70 & 0.3889 \\
$\mathrm{C}-3$ & 40 & 0.2667 & 58 & 0.3867 & 56.5 & 0.3767 \\
$\mathrm{C}-4$ & - & - & - & - & - & - \\
$\mathrm{C}-5$ & 52 & 0.2476 & 82 & 0.3905 & 74 & 0.3524 \\
$\mathrm{C}-6$ & 56 & 0.3111 & 82 & 0.4556 & 77 & 0.4278 \\
$\mathrm{C}-7$ & 40 & 0.2222 & 60 & 0.3333 & 59 & 0.3278 \\
$\mathrm{C}-8$ & 36 & 0.2400 & 56 & 0.3733 & 54 & 0.3600 \\
$\mathrm{C}-9$ & 60 & 0.2857 & 88 & 0.4190 & 86.5 & 0.4119 \\
\hline
\end{tabular}

with the positive slope $\left(k_{1}>0\right)$ until $\bar{\tau}=\overline{\tau_{u}}$. The BC segment is expressed as an oblique line with the negative slope $\left(k_{2}<0\right)$ until $\bar{\tau}=\overline{\tau_{r}}$. The CD segment is expressed as a horizontal line.

$$
\left\{\begin{array}{c}
S=0 \\
\bar{\tau}=k_{1} S+\overline{\tau_{s}} \\
\bar{\tau}=k_{2}\left(S-S_{u}\right)+\overline{\tau_{u}} \\
\bar{\tau}=\overline{\tau_{r}} \\
\left(0<\bar{\tau} \leq \overline{\tau_{u}}\right) \\
\left(0<S_{l} \leq S_{u}\right) \\
\left(S_{u}<S_{l} \leq S_{r}\right) \\
\left(S>S_{r}\right)
\end{array}\right\}
$$

where $k_{1}=\left(\overline{\tau_{u}}-\overline{\tau_{s}}\right) / S_{u}$ and $k_{2}=\left(\overline{\tau_{r}}-\overline{\tau_{u}}\right) /\left(S_{r}-S_{u}\right)$. 


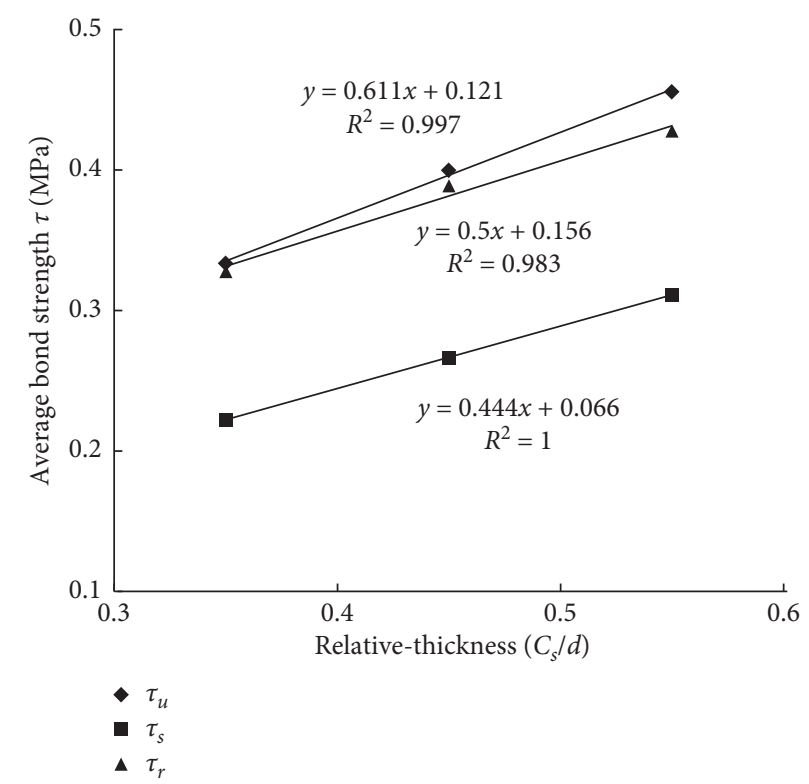

Figure 10: Relationship between $\bar{\tau}$ and $C_{s} / d$.

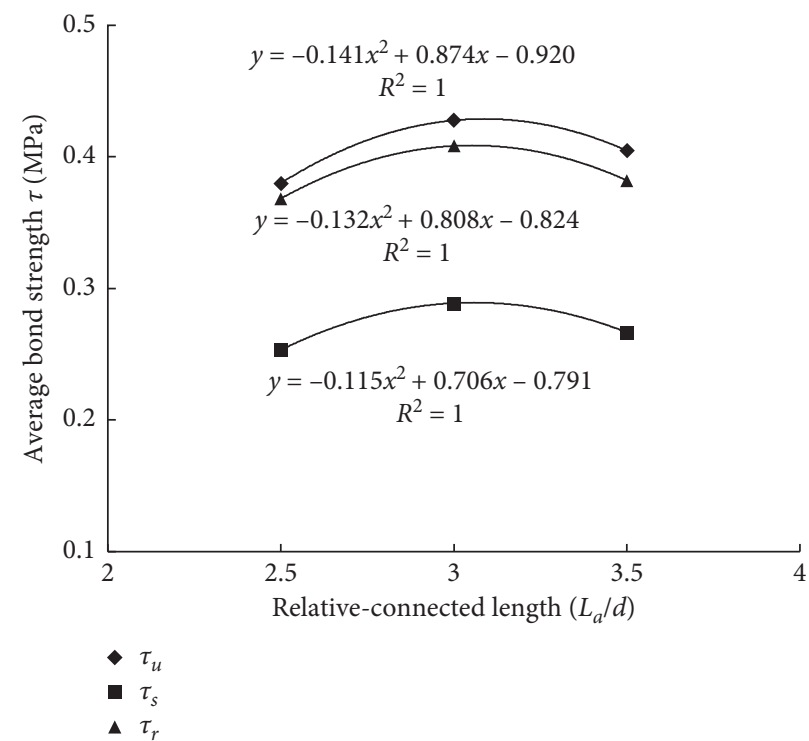

FIGURE 11: Relationship between $\bar{\tau}$ and $l_{a} / d$.

TABLE 3: Test results and fit results of average bond strength characteristics.

\begin{tabular}{|c|c|c|c|c|c|c|}
\hline \multirow{2}{*}{ Specimen no. } & \multicolumn{2}{|c|}{$\overline{\tau_{s}}(\mathrm{MPa})$} & \multicolumn{2}{|c|}{$\overline{\tau_{u}}(\mathrm{MPa})$} & \multicolumn{2}{|c|}{$\overline{\tau_{r}}(\mathrm{MPa})$} \\
\hline & Test result & Fit result & Test result & Fit result & Test result & Fit result \\
\hline $\mathrm{C} 1$ & - & - & - & - & - & - \\
\hline $\mathrm{C} 2$ & 0.267 & 0.263 & 0.400 & 0.400 & 0.389 & 0.367 \\
\hline C3 & 0.267 & 0.267 & 0.387 & 0.410 & 0.377 & 0.377 \\
\hline $\mathrm{C} 4$ & - & - & - & - & - & - \\
\hline $\mathrm{C} 5$ & 0.248 & 0.248 & 0.391 & 0.391 & 0.352 & 0.365 \\
\hline C6 & 0.311 & 0.303 & 0.456 & 0.439 & 0.428 & 0.384 \\
\hline $\mathrm{C} 7$ & 0.222 & 0.222 & 0.333 & 0.361 & 0.328 & 0.350 \\
\hline $\mathrm{C} 8$ & 0.240 & 0.231 & 0.373 & 0.373 & 0.360 & 0.360 \\
\hline $\mathrm{C} 9$ & 0.286 & 0.286 & 0.419 & 0.429 & 0.412 & 0.382 \\
\hline
\end{tabular}


TABLE 4: Test results of characteristic slip values.

\begin{tabular}{lcccc}
\hline Specimen no. & $S_{u}(\mathrm{~mm})$ & $\left(S_{u} / l_{a}\right) / 10^{-3}$ & $S_{r}(\mathrm{~mm})$ & $\left(S_{r} / l_{a}\right) / 10^{-3}$ \\
\hline C-1 & - & - & - & 12.11 \\
C-2 & 1.13 & 3.767 & 9.35 & 40.367 \\
C-3 & 1.10 & 4.400 & - & 37.400 \\
C-4 & - & - & 16.13 & 4 \\
C-5 & 1.38 & 3.943 & 12.37 & 41.233 \\
C-6 & 1.09 & 3.633 & 14.18 & 47.267 \\
C-7 & 1.15 & 3.833 & 10.39 & 41.560 \\
C-8 & 1.03 & 4.120 & 18.37 & 52.486 \\
C-9 & 1.41 & 4.029 & & \\
\hline
\end{tabular}

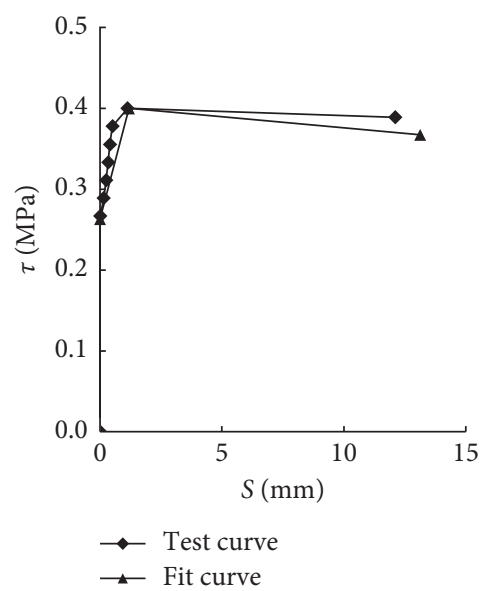

(a)

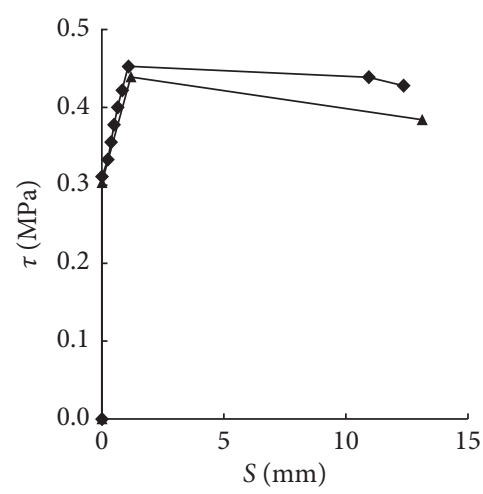

- Test curve

$\rightarrow$ Fit curve

(d)

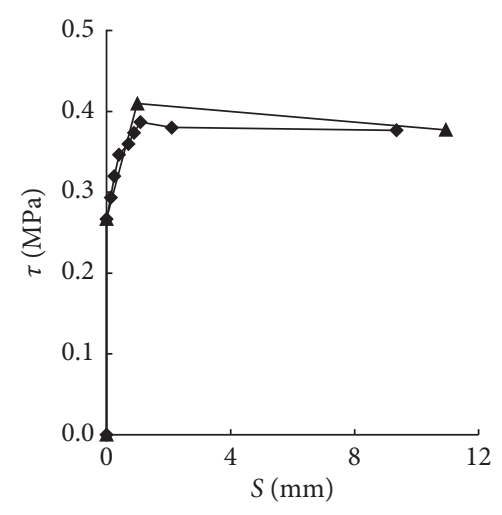

$\rightarrow$ Test curve

$\rightarrow$ Fit curve

(b)

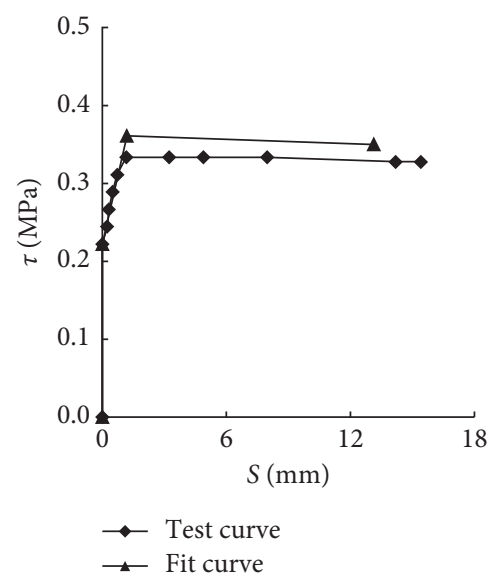

(e)

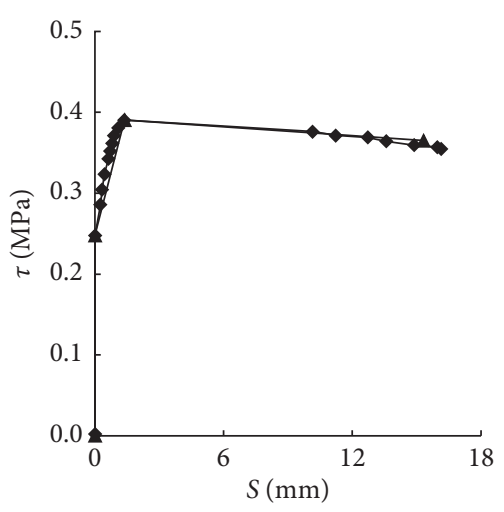

$\rightarrow$ Test curve

$\rightarrow$ Fit curve

(c)

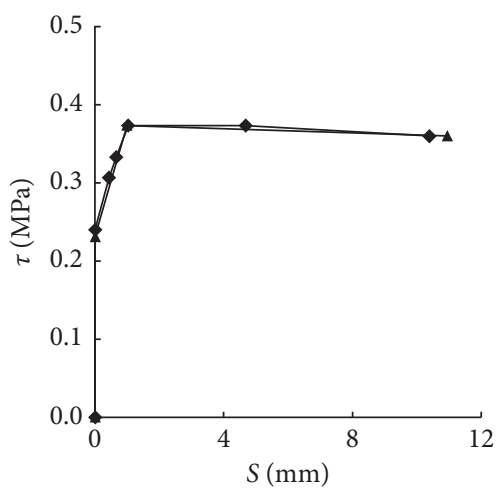

$\rightarrow$ Test curve

$\rightarrow$ Fit curve

(f)

Figure 12: Continued. 


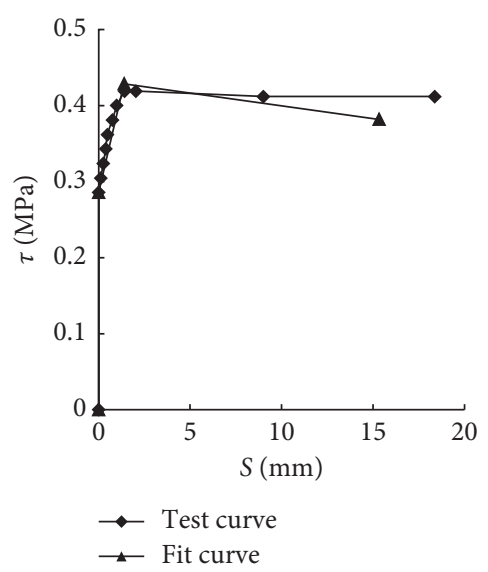

(g)

Figure 12: Fit curves and test curves of $\bar{\tau}-\mathrm{S}$ : (a) specimen C-2, (b) specimen C-3, (c) specimen C-5, (d) specimen C-6, (e) specimen C-7, (f) specimen C-8, and (g) specimen C-9.

In Figure 12, the fit curves and the test curves of $\bar{\tau}-S$ are illustrated. It can be found that the fit curves obtained by constitutive relationship equation (6) are almost consistent with the test curves, but there are still some deviations for some specimens, such as C-6 and C-7. The possible reason might be the formulas in equation (6) are proposed on the basis of the fit formulas in equation (4) of average bond strength characteristics and the fit formulas in equation (5) of slip characteristics. Although the accuracy of equations (4) and (5) is high, the error of these two equations is accumulated into the constitutive relationship formulas, which leads to some predicting errors between the test curves and the fit curves.

\section{Conclusion}

According to the experimental and analytical studies in the paper, several conclusions may be obtained as follows:

(1) The load-slip curves measured by the push-out test are summarized. According to the load-slip curves, the push-out test process of HSG specimens can be divided into four stages: no slip stage, slip stage, drop stage, and horizontal residual stage. The final cracking pattern of the push-out specimens is presented as three main types.

(2) Three characteristic values of initial slip bond strength, ultimate bond strength, and residual bond strength and two characteristic values of ultimate state slip and residual initial slip are defined. The calculating formulas of average bond strength characteristics and slip characteristics are obtained by statistical regression.

(3) Based on the analysis of the test results, the obtained ultimate average bond strength of HSG specimens was within [0.333-0.456] $\mathrm{MPa}$. Residual bond strength, approximately $90-98 \%$ of the ultimate, is provided by the friction between $\mathrm{H}$-shaped steel and gypsum. The main reason is that gypsum is microexpansible, and the friction on the interface is kept at a high level after the process of condensation, which provides a 3-directional constraint of internal measurement of the web and flange. The gypsum cover thickness and the steel-gypsum connected length have great influence on the average bond strength. By comparing with the test results, it is shown that the fitting formulas of average bond strength characteristics and slip characteristics have good accuracy.

(4) Based on the test results, the constitutive relationship between average bond strength and slip of HSG specimens is established. The influences of gypsum cover thickness and steel-gypsum connected length are considered at the same time. By comparing with the test curves, it is shown that the fitting formulas of the bond-slip constitutive relationship have favorable accuracy.

\section{Data Availability}

The data used to support the findings of this study are available from the corresponding author upon request.

\section{Conflicts of Interest}

The authors declare that they have no conflicts of interest.

\section{References}

[1] T. Sun, K.-J. Ma, C. Zhi-hua et al., "Study on structural influencing coefficient of multistory steel grid frame with gypsum-wall," Journal of Building Structure, vol. 34, no. 9, pp. 66-72, 2013, in Chinese.

[2] K.-J. Ma, G. Guo-Fu, H.-G. Zhang et al., "Research and application on space grid frame construction used in multi-story and tall buildings with energy saving and large bays," Spatial Structures, vol. 15, no. 3, pp. 62-84, 2009, in Chinese.

[3] T. Sun, H. Yu, K.-J. Ma et al., "Application of steel grid boxlike structure with gypsum wall in sub high-rise residences," Spatial Structures, vol. 20, no. 3, pp. 15-23, 2014, in Chinese. 
[4] S.-G. Cao, K.-J. Ma, W. Yan-Hui et al., "Application of assembled overall space steel grid cassette structure in the large span multi-story industrial buildings," Building Structures, vol. 43, no. 4, pp. 38-41, 2013, in Chinese.

[5] P. Deng and K.-J. Ma, "Research and application of the new assembled integral spatial steel grid "tub in tub" cassette structures in super high-rise buildings," Spatial Structures, vol. 18, no. 4, pp. 13-23, 2012, in Chinese.

[6] J. O. Bryson and R. G. Mathey, "Surface condition effect on bond strength of steel beams in concrete," Journal of ACI, vol. 59, no. 3, pp. 397-406, 1962.

[7] N. M. Hawkins, "Strength of concrete encased steel beams," Civil Engineering Transaction of the Institution of Australia Engineering, vol. 15, no. 1-2, pp. 39-46, 1973.

[8] C. W. Roeder, "Bond stress in embedded steel shapes in concrete," in Proceedings of the U.S./Japan Joint Seminar, ASCE, New York, NY, USA, pp. 227-240, 1985.

[9] G.-L. Sun and Y.-J. Wang, "Experimental study and calculation of axial force transfer performance at the end of stiff concrete columns," Journal of Architectural Structure, vol. 6, pp. 40-49, 1989.

[10] L. Hong and W. Jiang, "An experiment investigation of bonding constitutive relation on steel shapes and concrete," Journal of Northwest Institute of Construction Engineering, vol. 3, pp. 16-22, 1995.

[11] Y. Yang, X. Jian-Yang, and Z. Hong-Tie, "Analysis of bond strength in SRC structures," Building Structures, vol. 31, no. 7, pp. 31-34, 2001, in Chinese.

[12] S.-S. Zheng, G.-Z. Deng, Y. Yang et al., "Experimental study on bond-slip performance between steel shape and concrete in SRC structures," Engineering Mechanics, vol. 20, no. 5, pp. 63-69, 2003, in Chinese.

[13] L. Chen, J. Dai, Q. Jin, L. Chen, and X. Liu, "Refining bondslip constitutive relationship between checkered steel tube and concrete," Construction and Building Materials, vol. 79, pp. 153-164, 2015.

[14] Y. Yang, Z.-X. Guo, J.-Y. Xue et al., "Experiment study on bond slip behavior between section steel and concrete in SRC structures," Journal of Building Structure, vol. 26, no. 4, pp. 1-9, 2005, in Chinese.

[15] H. Zheng, X.-M. Hu, J.-R. Liu et al., "Experimental study of bond slip behavior between section steel and concrete in partially encased composite members," Industrial Constructions, vol. 42, no. 12, pp. 138-152, 2015.

[16] C. Liu, Z. Lv, G. Bai, and Y. Yin, "Experiment study on bond slip behavior between section steel and RAC in SRRC structures," Construction and Building Materials, vol. 175, pp. 104-114, 2018.

[17] L. Bai, J. Yu, M. Zhang, and T. Zhou, "Experimental study on the bond behavior between $\mathrm{H}$-shaped steel and engineered cementitious composites," Construction and Building Materials, vol. 196, pp. 214-232, 2019. 